\title{
AN EXPERIMENTAL INVESTIGATION OF HYPERGOLIC GINITION DELAY OF HYDROGEN PEROXIDE WITH FUEL MIXTURES
}

\author{
John A. Blevins ${ }^{*}$, Rudy Gostowski ${ }^{\dagger}$, Silvio Chianese ${ }^{\ddagger}$ \\ NASA Marshall Space Flight Center \\ Propulsion Research Center \\ $M S F C, A L 35812$
}

\begin{abstract}
An experimental investigation of hypergolicity and ignition delay of fuel mixtures with hydrogen peroxide is presented. Example results of high speed photography and schleiren from drop tests are shown. Also, a discussion of the sensitivity to experimental parameters such as drop size and subsequent uncertainty considerations of ignition delay results is presented. It is shown that using the described setup on the mixtures presented, the precision uncertainty is on the order of $6 \%$ of average ignition delay and $5 \%$ of average decomposition delay. This represents sufficient repeatability for first order discrimination of ignition delay for propellant development and screening. Two mixtures, each using commonly available amines and transition metal compounds, are presented as examples that result in ignition delays on the order of 10 milliseconds.
\end{abstract}

\section{Introduction}

The term hypergolic is used to describe the spontaneous ignition of a fuel and an oxidizer on contact. Hypergolic propellants are advantageous for several rocket mission profiles, most notably, when multiple ignitions are essential for mission success, such as with the Apollo Lunar Lander, reaction control systems (RCS), and orbital maneuvering systems (OMS). Other applications include use as a starting agent for rockets powered by other propellants.

Hydrogen peroxide, $\mathrm{H}_{2} \mathrm{O}_{2}$, was the first oxidizer used as an operational hypergolic propellant when employed in the Messerschmidt Me-163 Comet rocket plane in 1944.1,2 Subsequently, peroxide has found applications in the rocket industry as a monopropellant, and as an aircraft rocket boost propellant (NF-104), ${ }^{3}$ but not as part of a hypergolic system. Some notable manned applications of $\mathrm{H}_{2} \mathrm{O}_{2}$ include attitude control for the X-15, Bell X-1B, Mercury program and Soyuz systems.

Peroxide has several properties that can provide system advantages when compared to the traditional hypergolic oxidizers, nitric acid compounds and nitrogen tetroxide. These properties include higher density, lower vapor pressure, a less corrosive nature and the potential to be hypergolic with compounds less hazardous than hydrazine fuels, which are typically used in hypergolic applications. Additionally, peroxide decomposition products and combustion products with typical fuels are more environmentally safe than other monopropellants and hypergolic oxidizers. Along with advantages, peroxide provides challenges to implementation, such as thermal management and materials compatibility.

Interest in using peroxide in hypergolic applications has renewed over the last decade.4-11 The use of a catalyst for the promotion of decomposition of hydrogen peroxide dates to German use of calcium permanganate in methanol with $80 \%$ peroxide as a hypergolic combination in the Me $163 .^{2}$ Recent studies have employed this approach, using a metal chelate as a "promotor" with alcohols and ketones. ${ }^{4,5,6.7}$ References 6 and 7 present discussions of the use of amines with metal chelates as a catalyst for hypergolic ignition. Reference 6 goes on to discuss amines and metal chelates to be mixed with fuels that are non-miscible with peroxide by themselves, such as kerosene.

This article presents a discussion of experimental techniques, with emphasis on the use of high speed photography and schleiren images to determine decomposition and ignition times. Additionally, data of fuel blends comprised of $\mathrm{N}, \mathrm{N}$-dimethylbutylamine and N,N-dimethylhexylamine mixed with cobalt (II) 2-ethylhexanoate and $98 \%$ concentration hydrogen peroxide are presented as sample data. Many similar compounds have been presented in open literature,

\footnotetext{
${ }^{*}$ Propulsion Researcher, Senior Member AIAA

†Senior Chemist

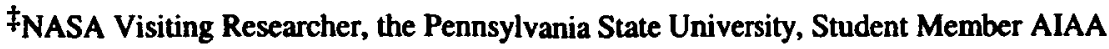

Copyright $\Theta 2004$ by the American Institute of Aeronautics and Astronautics, Inc. No copyright is asserted in the United States under Title 17, U.S. Code. The U.S. Government has a royalty-free license to exercise all rights under the copyright claimed herein for Government purposes. All other rights are reserved by the copyright owner. 
with the most exhaustive list by Melof and Grubelichh. ${ }^{7}$

\section{Considerations in Hypergolic Propellant} Characterization

Ignition occurs when heat generation becomes greater than heat absorption to the surrounding media, resulting in thermochemical sustainment of combustion. ${ }^{12}$ In hypergolic ignition systems, heat is provided solely by a chemical reaction of the fuel and oxidizer upon contact. Since the propellants are mixed as liquids, initial reactions are necessarily liquid phase reactions. In fact, some previous studies show that some propellant combinations that are hypergolic in the liquid phase, are not hypergolic as gases. ${ }^{13}$ Mechanisms of hypergolic chain reactions have been previously considered, with the emphasis on nitric acid and nitrogen tetroxide oxidizing agents. ${ }^{13-17}$

Hypergolic propellant combinations that utilize hydrogen peroxide are best characterized by two different reactions. One reaction is the exothermic decomposition of the peroxide and the other, the local autoignition of heated oxygen and fuel vapor. This differs considerably from the nitic acid and nitrogen tetroxide oxidizers, which are proposed to initiate an exothermic nitration step sufficient for combustion reactions to continue. In peroxide, a fast decomposition reaction (quick energy deposition) does not guarantee the subsequent autoignition step, though it does aid considerably, by lowering the local activation energy required for autoignition. So, in theory, a catalyst mechanism that promotes more rapid decomposition may afford a fuel hypergolic with peroxide that with a slower decomposition would not be hypergolic.

\section{Experimental Determination of Ignition Delay}

One of the most important parameters for hypergolic propellant development is ignition delay. Ignition delay is critical for injector design, starting sequence and in some cases, application limitations, (e.g. RCS must have ignition delays to allow multiple starts and stops within $100 \mathrm{~ms}$ to meet current mission profiles). Ignition delay, the time between fluid contact and ignition is a function of mixing, kinetics, heat transfer, initial temperature, ambient pressure, and other local environment conditions. For initial screening, many of the application environment conditions are not considered because of the complexity of such a test. Historically, the initial testing of combinations thought to be hypergolic have been performed by dropping one of the propellants into a small volume of the other propellant and observing the subsequent reaction. $1,7,8,11,18,19,20$

The underlying premise of drop testing is to provide replicated fluid mechanics, so that the heat of the reaction, subsequent phase change and reaction time can be identified. However, many previous studies had difficulty with repeatability and lab to lab comparisons, as indicated by Clark'. More recent studies have indicated improvement in the precision uncertainty, 19,20 including the study presented in this paper. Logically, drop testing should provide the best environment for repeatable experimental results, though, it should be recognized that the drop testing differs considerably from the end application that includes aggressive forced mixing and thermal transients, among other phenomena.

Many diagnostic tools have been used in drop testing which vary from naked eye observation, to photodiode, to Raman spectroscopy, 19,20 the later, a recent effort to better understand the mixing and subsequent chemical chain reactions in addition to ignition delay. The study presented in this paper utilized both high speed photography and schleiren. Both techniques have had limited application in this type of testing, and are mentioned only briefly in the literature. ${ }^{1}$ Though somewhat more complex than the method of using photodiode measurements for ignition delay determination, high speed images afford observation of decomposition and ignition in hydrogen peroxide reactions. Also, if sufficient time resolution is employed, the ignition location can be observed. This provides significant insight into the ability to replicate conditions from one test to another and to identify anomalous tests.

\section{Experimental Procedure}

As previously indicated, drop testing was used to determine the relative ignition delay between various fuel mixtures and a variety of hydrogen peroxide concentrations. Many of the mixtures are not discussed in this paper due to confidential relationships that prohibit release of mixtures. However, limited fuel combinations of commercially available constuents are discussed to illustrate the experimental techniques used in the drop testing, and to provide insight into hypergolic ignition of hydrogen peroxide.

The experimental procedure was to contain 300 microiliters of the fuel blend in a quartz cuvette, and to drop 10.7 microliters of approximately $98 \%$ hydrogen peroxide. Peroxide batches were evaluated for concentration by means of measuring the refractive index. 


\section{Propellants}

The amines discussed in this paper are $\mathrm{N}, \mathrm{N}$ dimethylbutylamine and $\mathrm{N}, \mathrm{N}$-dimethyhexolamine. These amines were chosen because of availability and of the similarity in chemical structure, but considerably different thermophysical properties, such as vapor pressure and boiling point, as listed in Table 1. The transition metal catalyst was a stock mixture of $65 \%$ by weight cobalt (II) 2ethylhexanoate and $35 \%$ by weight mineral oil. It should be noted that the mineral oil should detract from the ignition performance of the blend since it is a heavy hydrocarbon distillate. The mineral oil is added in the stock mixture as a stabilizing agent for the transition metal catalyst. The amines were mixed with the catalyst mixture on a $95 \%$ by volume amine and 5\% transition metal catalyst mixture. Additionally, fuels non-miscible with hydrogen peroxide such as pentane and octane were tested using the same catalyst mixture, but are not discussed because they were not hypergolic regardless of the amount of transitional metal catalyst added.

\section{Experimental Diagnostics}

Drop test experiments were used with various forms of high speed video imaging. The different imaging methods employed in this study include photography, shadowgraphy, and schleiren. Figure 1 is a schematic of the setup in photography and schleiren configurations. The three diagnostic setups require increasing complexity, but afford increasing detail for observations during the experiment. Schleiren and shadowgraphy afford an advantage over photography by providing visualization of the density variations, with schleiren providing the most detail and sharpest density gradient image. As schleiren and shadowgraphy are well established methods, a detailed discussion of the methods will not be presented in this paper. However, if the reader seeks further insight, the text by Settles ${ }^{21}$ is highly recommended.

\section{Shakedown and Uncertainty Considerations}

As previously noted, a consideration for performing drop testing is the precision uncertainty, or repeatability of replicated experiments. ${ }^{22}$ In this case, the authors decided to evaluate test parameters such as drop height, pool volume, drop volume, the difference between testing in a cuvette and testing on a dimpled slide, and dropping fuel into oxidizer to ascertain a measure of the sensitivity of parameters to the experiments. The results are qualitatively summarized in Table 2.
The results indicated that dropping fuel into a pool of peroxide provides results with large precision uncertainties, on the order of $50 \%$ of nominal value, with some anomalous tests resulting in no ignition. Further review of this method using higher time resolution schleiren (2000 frames per second) revealed that in this test condition, the rapid decomposition of peroxide was sufficiently violent to evacuate the cuvette resulting in an unpredictable ignition site, most often far from the decomposing peroxide. Conversely when dropping peroxide into the fuel, the ignition location is almost always just above the fuel pool surface. Historically, drop testing has been accomplished by dropping the oxidizer, despite more difficult handling. This is particularly important when working with peroxide due to the greater volume change of peroxide, and the required two reaction nature as noted previously. In fact, it is inappropriate to label this experimental parameter as a "sensitivity," but rather, dropping fuel into the peroxide renders the test ineffective for providing adequate ignition delay screening between propellant combinations, though it can be used to verify ignition.

Tests using a dimpled slide instead of a cuvette provided ignition delay results within the repeatability of the cuvette tests, with similar precision uncertainties, so, it is a parameter to which the test is apparently insensitive. A few words on the sensitivity of drop size is warranted. In our testing, we saw very limited effect of drop size over the range of 5 microliters to 25 microliters in size. The precision uncertainty was slightly higher with larger drop sizes. It should be noted that drops in this study are small compared to many experiments in the scientific community, and therefore, the results may be invalid for other setups. Additionally, in this study, no effort was made to evaluate local equivalence ratios. Several hypergolic studies, particularly those with impinging streams, go to great extent to worry about fuel to oxidizer ratios. However, in basic drop testing, the goal is to provide essentially an unlimited amount of fuel for the oxidizer drop so that no sensitivity to the local mixing would be present in our tests.

The bias or systematic uncertainty is determined by the time resolution of the camera. With the present setup, it was found that 2000 frames per second provided a sufficiently low bias uncertainty. This is an important factor in the experimental setup, as higher frame rates generally are more expensive both fiscally and computationally. Also, higher frame rates require more lighting. So, in short, with mixtures like those considered in this study, 0.5 
millisecond resolution was sufficient to accurately measure ignition events.

\section{Experimental Results}

Typical high speed camera images and schleiren images are presented in Figures 2 and 3. In both data sets, the shutter is open during time between data marks, so each image is an presents integrated events from the prior image. Examples of shadowgraphy are not presented, but are most similar to schleiren. Since the setups are very similar, it is the authors recommendation to use schleiren since little additional effort is required and more detail is afforded.

Data for Figure 2 was taken at a rate of 1000 frames per second (fps) of a fuel mixture not discussed in this paper. Important events such as the drop passing the meniscus on the cuvette (time $=0$ ), onset of decomposition $(7 \mathrm{~ms})$, and ignition $(16 \mathrm{~ms})$ are easily identified from the data.

Figure 3 was taken at 2000 fps of N,Ndimethybutylamine. The stong adhesive properties and high vapor pressure are evident by the wicking of fuel onto the cuvette sides, as can be seen. Again the important events can be easily identified, such as decomposition at 5.5 milliseconds and the initial cornels of autoignition at $\mathbf{1 0 . 0}$ milliseconds. Table 3 presents the measured decomposition and ignition delay times for the two amine based mixtures presented earlier.

One of the advantages of the schleiren images is the identification of the pressure expansion source, or the autoignition location. While it can be observed reasonably well with photography, the ignition location is most identifiable in schleiren imagery. The experimental results demonstrate a relatively fast ignition time. Additionally, despite considerably different thermophysical properties, the ignition delays are similar. This was somewhat unexpected by the authors as we considered that vapor pressure would play a more prominent role. However, this can be noteworthy in developing an optimized blend for applications. Given similar mixtures, lower vapor pressure mixtures will likely afford easier handling.

\section{Conclusion}

High concentration hydrogen peroxide can be mated with fuel mixtures, such as the amines with transition metal chelates presented in this paper, to provide a vigorous hypergolic propellant combination with ignition delays on the order of 10 milliseconds. hydrogen peroxide and fuel mixture combinations are likely to require less intensive operations prior to, and upon return from, launch. However, the advantages are offset somewhat by concerns of storage stability and thermal management on mission. Because of these concerns, near term applications of hydrogen peroxide as a hypergolic are likely to be limited to OMS and RCS that do not have exceeding long mission life.

The use of high speed schleiren imaging in drop tests affords clear diagnostic ability to determine decomposition and ignition delay times. Additionally, schleiren provides better identification of the ignition location than photographic images, thereby, allowing anomalous testing to be more easily identified.

\section{References}

'Clark, John D., Ignition! An Informal History of Liquid Rocket Propellants, Rutgers University Press, 1972.

${ }^{2}$ Wofgang, Spate, Top Secret Bird: The Luftwaffe's Me-163 Comet, Independent Publishers, 1989.d

${ }^{3}$ http://www.wpafb.af.mil/museum/fta/fta597.htm

${ }^{4}$ Funk, J. Heister, S. D., and Rusek, J. J., 'Reaction Zones for Impinging Jets and Sheets," AIAA 20024174, July 2002.

${ }^{5}$ Long, M. R., Anderson, W. E., and Humble, R. W., "Bi-Centrifugal Swirl Injector Development for Hydrogen Peroxide and Non-Toxic Hypergolic Miscible Fuels," AIAA 2002-4026, July 2002.

'Dobbins, T. A., "A Novel Catalyst System for Rendering Organic Propellants Hypergolic with Hydrogen Peroxide," AIAA 2002-4340, July 2002.

${ }^{7}$ Melof, B, M., and Grubelich, M. C., "Investigation of Hypergolic Fuels with Hydrogen Peroxide," AIAA-2001-3837, 37 ${ }^{\text {th }}$ Propulsion Conference, Salt Lake City, UT, July 2001.

${ }^{8}$ Frolik, S. A. and Austin, B. L., "Development of Hypergolic Liquid Fuels for Use with Hydrogen Peroxide," AIAA 2001-0013, January 2001.

${ }^{9}$ Humble, R. W., "Bipropellant Engine Development Using Hydrogen Peroxide and a Hypergolic Fuel," AIAA 2000-3554, July 2000.

${ }^{10}$ Funk, J. E., Heister, S. D., Humble, R., and Purcell, N., "Development Testing of Non-Toxic Storable Hypergolic Liquid Propellants," AIAA-99-2878, 35 Joint Propulsion Conference, Los Angeles, CA, June 1999. 
${ }^{1}$ Rusek, J. J., and Lormand, B., Non-Toxic Hypergolic Miscible Fuels for In-situ Decomposition of Rocket-Grade Hydrogen Peroxide, $1^{\text {st }}$ Annual International Symp. of High Test Peroxide, 1998.

${ }^{12}$ Glassman, Irvin, Combustion, $3^{\text {rd }}$ ed. Academic Press, 1996.

${ }^{13}$ Kulkarni, S. G., "Mechanism of Hypergolic Ignition," J. of Armament Studies, Vol XVI, No. 2, 1980.

${ }^{14}$ Durgapal. U. C., et al, "Studies on Hypergolicity of Several Liquid Fuels with Fuming Nitric Acid as Oxidizers," Propellants, Explosives, Pyrotechnics, Vol. 12, pp. 149-153, 1987.

15Panda, S., Kulkarni, S., Prabhakaran, C., "Synergestic Hypergolic Ingnition of Blends of Dienes and Dienophiles with Red Fuming Nitric Acid as Oxidizers," Combustion and Flame, Vol. 76, pp.107-110, 1989.

${ }^{16} \mathrm{Jain}$, S. R. and Murthy, K. N., "Temperature Profile and Ignition Delay Studies on Hypergolic Systems," Combustion and Flame, Vol. 81, pp. 403-405, 1990.

17Jain, S. R., and Mimani, T., "Temperature Profiles of Reactive Biliquid Systems Prior to Ignition,"
Journal of Thermal Analysis, Vol. 36, pp. 2393-2406, 1990.

${ }^{18}$ Broatch, J. D., "An Apparatus for the Measurement of Ignition Delays of Self-Igniting Fuels," Fuel, Vol. 24, pp. 106-109, 1950.

${ }^{19}$ Mays, L. O., Farmer, M. J., and Smith, J. E., "A Laser Diagnostic Technique to Measure Chemical Delay Time in Hypergolic Combustion," Combustion Sci. and Tech., Vol. 134, pp. 127-138, 1998.

${ }^{20}$ Hampton, C. S., Ramesh, K. K., and Smith, J. E., "Importance of Chemical Delay Time in Understanding Hypergolic Ignition Delay Behaviors," AIAA 2003-1359, January 2003.

${ }^{21}$ Settles, G. S., Schlieren and Shadowgraph Techniques, Springer-Verlag 2001.

${ }^{22}$ Coleman, H. W. and Steele, G. Experimentation and Uncertainty Analysis for Engineers, $2^{\text {nd }}$ Ed., John Wiley \& Sons, 1999.

Table 1. Thermophysical Properties of Tested Amines

\begin{tabular}{|c|c|c|c|c|c|c|}
\hline Amine & $\begin{array}{c}\text { Molecular } \\
\text { Weight }\end{array}$ & $\begin{array}{c}\text { Vapor pressure } \\
\text { at 25 }{ }^{\circ} \mathbf{C} \\
(\mathbf{m m ~ H g})\end{array}$ & $\begin{array}{c}\text { Boiling } \\
\text { point } \\
\left({ }^{\circ} \mathbf{C}\right)\end{array}$ & $\begin{array}{c}\text { Density } \\
(\mathbf{g} / \mathbf{m l})\end{array}$ & $\begin{array}{c}\text { Heat of } \\
\text { Formation } \\
(\mathbf{k c a l} / \mathbf{m o l})\end{array}$ & $\begin{array}{c}\text { Flash Point } \\
\left({ }^{\circ} \mathbf{C}\right)\end{array}$ \\
\hline N,N-dimethylbutylamine & 101.2 & 46 & 93 & 0.721 & -19.6 & -4 \\
\hline N,N-dimethylhexylamine & 129.2 & 4 & 146 & 0.744 & -32.5 & 34 \\
\hline
\end{tabular}

Table 2. Sensitivity Test Results

\begin{tabular}{|c|c|c|}
\hline Test Parameter & Range of Testing & Outcome \\
\hline Drop height & $1 / 2 "$ to $3^{\prime \prime}$ & No measurable difference in average ignition delay \\
\hline Drop volume & 5 to 25 microliters & No measurable difference in average ignition delay \\
\hline Pool volume & $\begin{array}{c}50 \text { to } 400 \\
\text { microliters }\end{array}$ & $\begin{array}{c}\text { Low pool volumes that do not sufficiently wet the } \\
\text { bottom of the cuvette result in slower igntion }\end{array}$ \\
\hline $\begin{array}{c}\text { Cuvette vs. dimpled } \\
\text { slide }\end{array}$ & - & No measurable difference in average ignition delay \\
\hline $\begin{array}{c}\text { Fuel drop vs. } \mathrm{H}_{2} \mathrm{O}_{2} \\
\text { drop }\end{array}$ & - & $\begin{array}{c}\text { Fuel drops = ignition delay increase + precision uncertainty }= \pm 50 \% \\
\mathrm{H}_{2} \mathrm{O}_{2} \text { drops = ignition delay precision uncertainty } \pm 6 \%\end{array}$ \\
\hline
\end{tabular}

Table 3. Decomposition and Ignition Delay

\begin{tabular}{|c|c|c|}
\hline Amine & Decomposition Delay (ms) & Ignition Delay (ms) \\
\hline N,N-dimethylbutylamine & $5.2 \pm 0.3$ & $9.8 \pm 0.7$ \\
\hline N,N-dimethylhexylamine & $6.1 \pm 0.3$ & $12.7 \pm 0.8$ \\
\hline
\end{tabular}




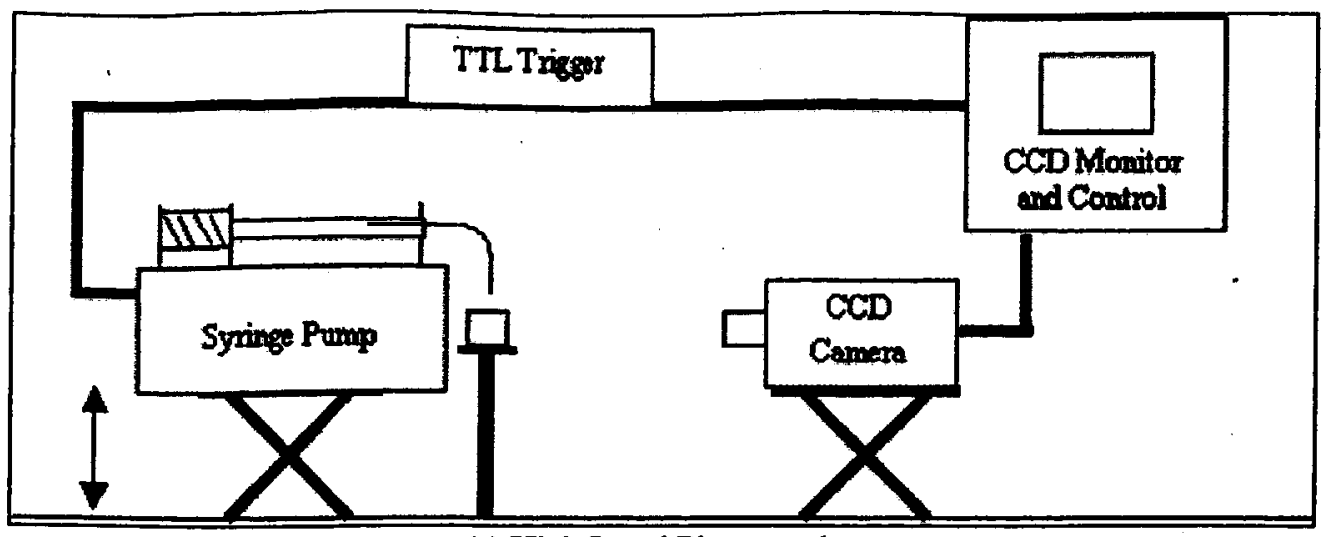

(a) High Speed Photography

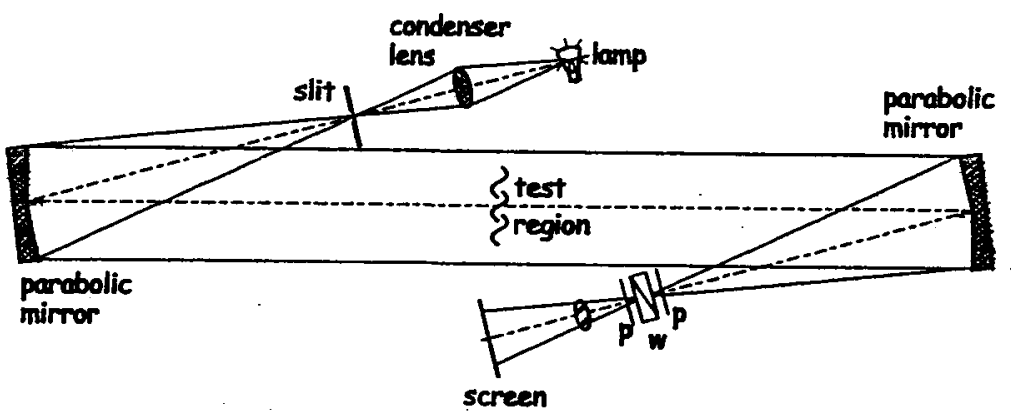

(b) Schleiren

Figure 1. Experimental Setup 


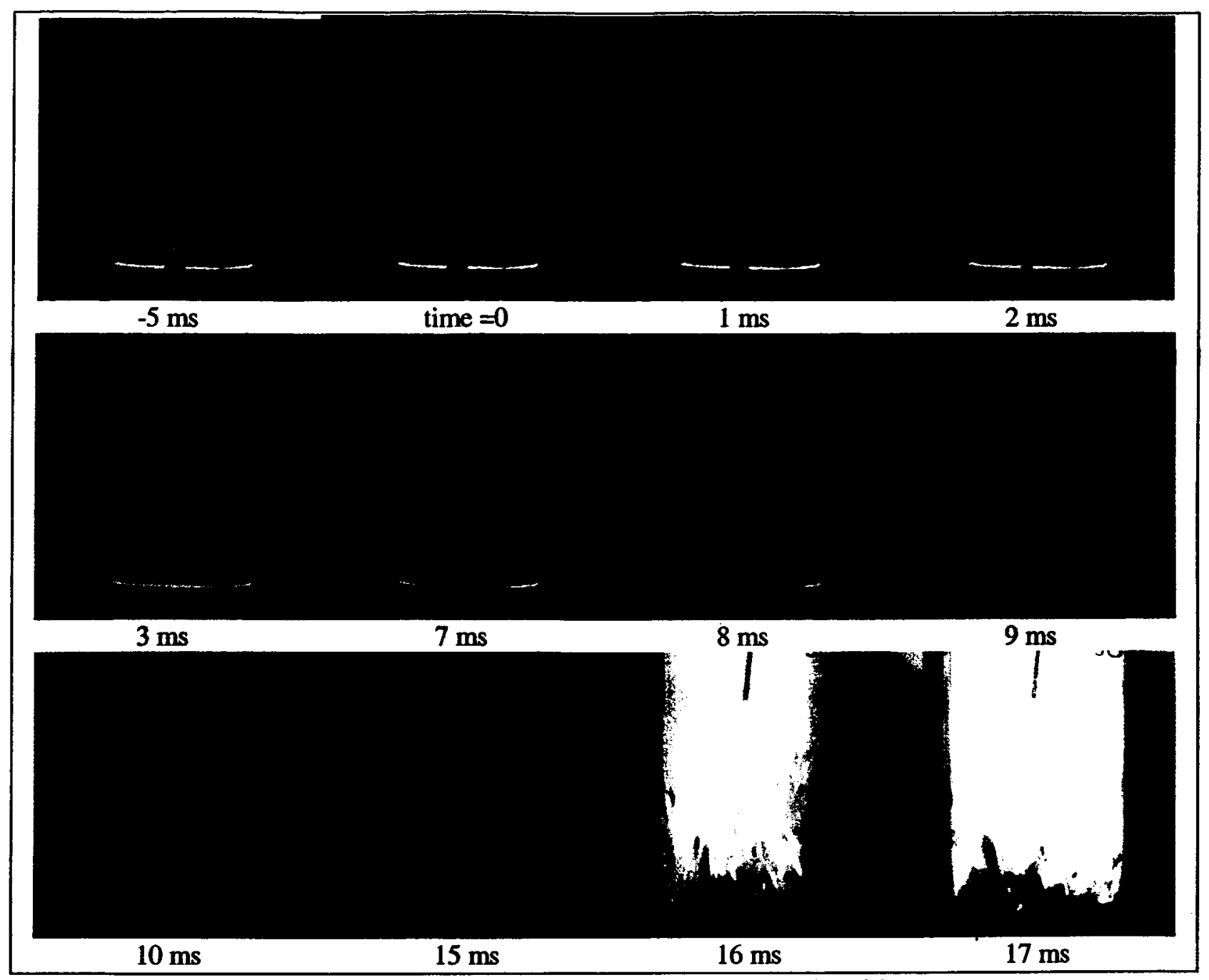

Figure 2. Example Data for Decomposition and Ignition 


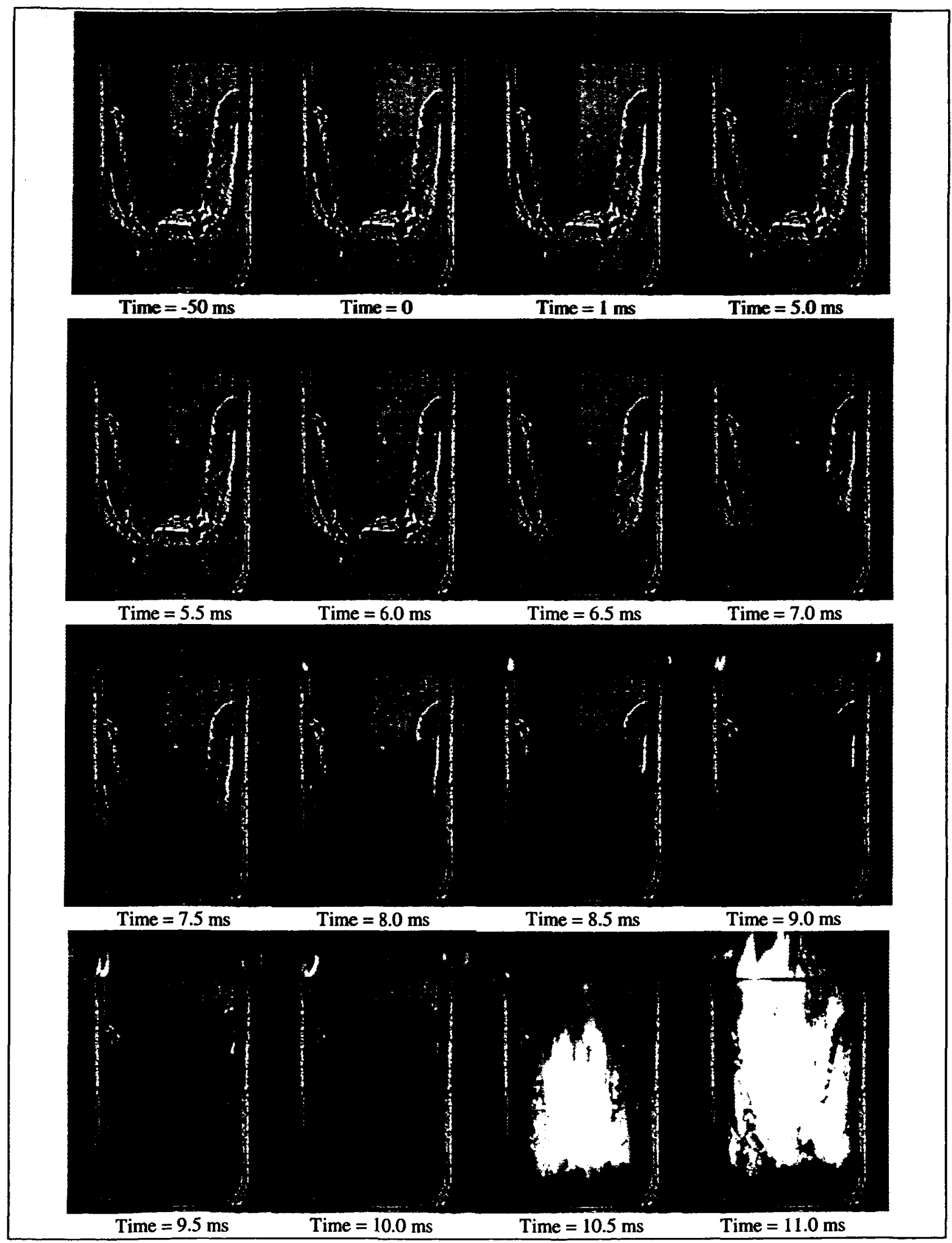

Figure 2. Series of Drop Test Schleiren Images 